\title{
Lipomatous hamartoma of Hoffmann-Zurhelle with papillomatous appearance
}

\section{Introduction}

A 28-year-old woman with no significant pathological history admitted to dermatology consultation for nodules and asymptomatic tumors in the left thigh since the age of 10, gradually increasing in size. The clinical examination found papules and tumors multi-lobed flesh-soft, are grouped in closets in zosteriform arrangement at the inner side of the left thigh (Figure 1), with a papillomatous surface in places (arrow, Figure 2). The rest of the dermatological and somatic examination was peculiar. The histological study of a deep biopsy fragment with papillomatous surface showed a protruding epidermis with irregular relief, surmounted by a slightly thickened ortho keratotic layer in places (Figures 3-4).

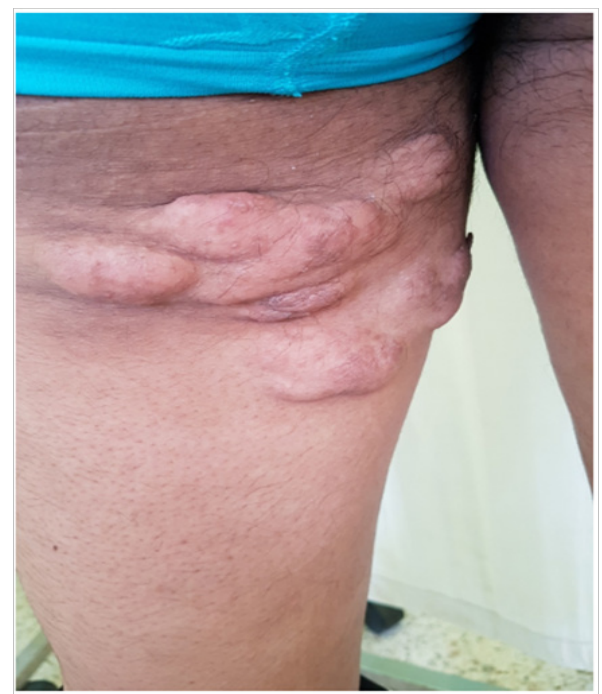

Figure I papules and tumors multi-lobed flesh-soft, are grouped in closets in zosteriform arrangement at the inner side of the left thigh.

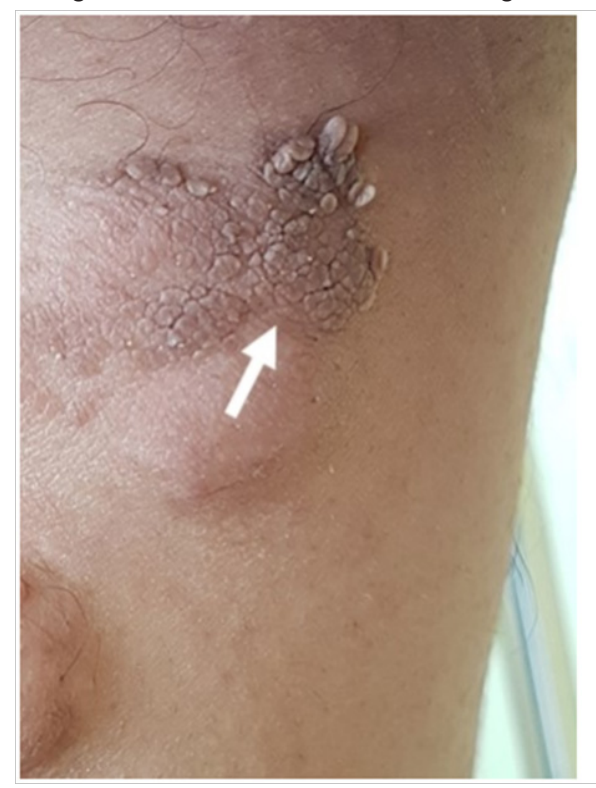

Figure 2 lesions with papillomatous surface in places.
Volume 3 Issue 3 - 2019

\section{Mounia Bennani, Selma Benkirane, Sara Elloudi, Hanane Baybay, Fatima Zahra Mernissi}

Department of Dermatology, University Hospital Hassan II, Morocco

Correspondence: Mounia Bennani, Dermatology, University Hospital Hassan II, Morocco, Tel 002 I 2660 I 20505,

Email mouniaabennani24@gmail.com

Received: March 07, 2019 | Published: June 13, 2019

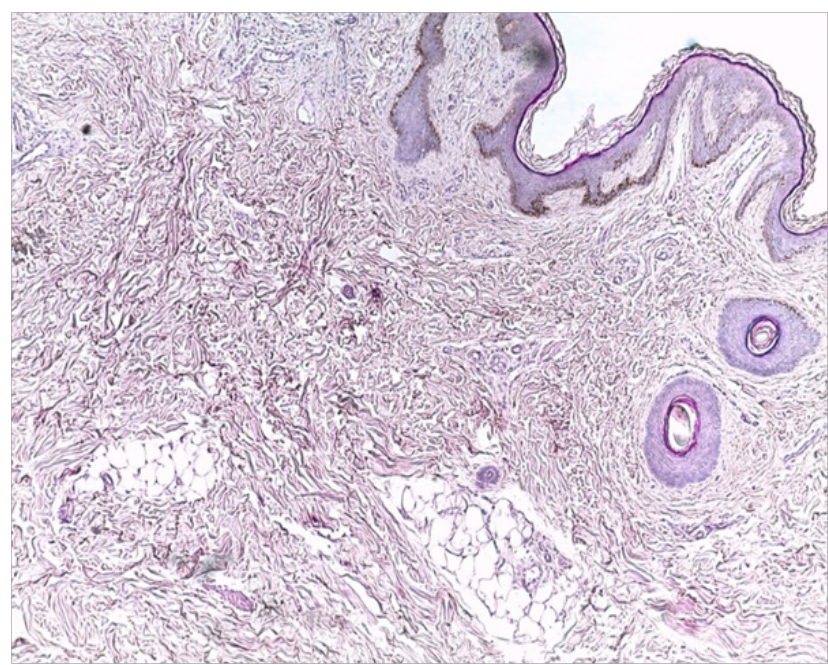

Figure 3 HES staining Mx50-Adipose lobules located in the dermis.

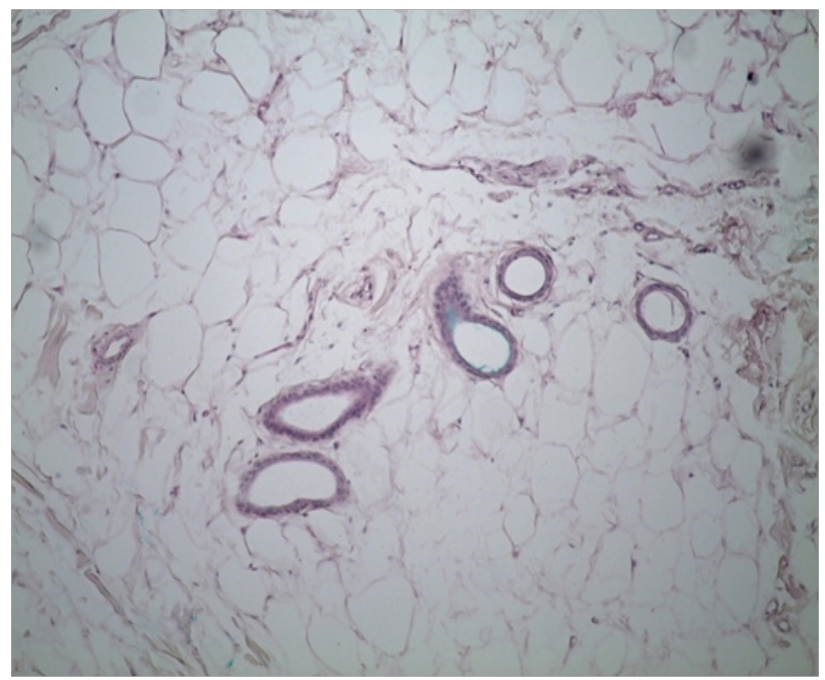

Figure 4 HES staining Mx100-sweat glands dissociated by adipose tissue. 
The axis of the formation consists of a loose felting of collagenous fibers associated with mature adipocyte cell lobules, high located in the superficial, medium and deep reticular dermis without connection with the hypodermis in places, with a good number of vessels. Without any cytopathic sign of HPV infection.

These clinical and histological findings supported the diagnosis of superficial lipomatous hamartoma. Surgical excision of large tumors has been proposed.

\section{Acknowledgments}

None.

\section{Conflicts of interest}

Author declares that there is no conflict of interest 